\title{
GESTÃo ESTRATÉGICA DE CUSTOS EM UMA ENTIDADE FECHADA DE PREVIDÊNCIA COMPLEMENTAR
}

\section{RESUMO}

Diante das especulações atuais que concernem à reforma da previdência no Brasil, proposta pelo Governo Federal, mostra-se oportuna a análise estratégica estrutural do setor de previdência complementar fechada no país. Assim, este estudo tem por objetivo identificar como se caracteriza a cadeia de valor, o posicionamento estratégico e os cost drivers (determinantes de custos) em um Fundo de Pensão brasileiro, adaptando as diretrizes originalmente propostas por Shank e Govindarajan (1997) e Costa (2011). Para tanto, foi realizado um estudo de caso, com entrevistas semiestruturadas, observação e análise documental. Os resultados apresentam as configurações, elos e atividades existentes na cadeia de valor da organização, evidenciando os fornecedores estratégicos, desde a consultoria atuarial, de investimentos e jurídica; as atividades internas da entidade, que se iniciam na captação de participantes, arrecadação das contribuições, aplicação e concessão de benefícios; e os participantes que recebem os benefícios, sejam de aposentadoria, auxílio-doença, pensão e pecúlio. Fatores externos também são demonstrados, além do posicionamento estratégico da entidade. A análise dos determinantes de custos demonstra a importância do comprometimento, experiência, qualidade, tecnologia, modelo de gestão, escopo, escala e fatores institucionais nos custos da organização.

Palavras-chave: Fundos de Pensão. Cadeia de Valor. Posicionamento Estratégico. Determinantes de Custos.

\section{STRATEGIC COST MANAGEMENT IN A CLOSED COMPLEMENTARY PENSION ENTITY}

\begin{abstract}
Given the current speculation that concern the pension reform in Brazil, proposed by the Federal Government, is timely strategic analysis of private pension sector structural closed in the country. Thus, this study aims to identify how its value chain, strategic positioning and the cost drivers (of costs) in a Brazilian Pension Fund, adapting the guidelines originally proposed by Shank and Govindarajan (1997) and Costa (2011). To this end, we conducted a case study with semi-structured interviews, observation and document analysis. The results present the settings, links and existing activities in the value chain, highlighting the strategic suppliers, since actuarial consultancy, investment and legal; the internal activities of the entity, that start in attracting participants contributions collection, application and granting of benefits; and participants who receive the benefits of retirement, sickness, pension and annuity. External factors are also shown, in addition to the strategic position of the entity. The analysis of the determinants of costs demonstrates the importance of the commitment, experience, quality, technology, model management, scope, scale, and institutional factors in the costs of the organization.
\end{abstract}

Keywords: Pension Fund. Value Chain. Strategic Positioning. Cost Drivers. 


\section{GESTIÓN ESTRATÉGICA DE COSTOS EN UNA ENTIDAD CERRADA DE SEGURIDAD COMPLEMENTARIA}

\section{RESUMEN}

Ante las especulaciones actuales que conciernen a la reforma de la seguridad en Brasil, propuesta por el Gobierno Federal, se muestra oportuna el análisis estratégico estructural del sector de seguridad complementaria cerrada en el país. Por lo tanto, este estudio tiene por objetivo identificar cómo se caracteriza la cadena de valor, el posicionamiento estratégico y los cost drivers (determinantes de costos) en un Fondo de Pensión brasileño, adaptando las directrices originalmente propuestas por Shank y Govindarajan (1997) y Costa 2011). Para ello, se realizó un estudio de caso, con entrevistas semiestructuradas, observación y análisis documental. Los resultados presentan las configuraciones, eslabones y actividades existentes en la cadena de valor de la org anización, evidenciando los proveedores estratégicos, desde la consultoría actuarial, de inversiones y jurídica; las actividades internas de la entidad, que se inician en la captación de participantes, recaudación de las contribuciones, aplicación y conces ión de beneficios; y los participantes que reciben los beneficios, sean de jubilación, ayuda-enfermedad, pensión y peculio. Los factores externos también se demuestran, además del posicionamiento estratégico de la entidad. El análisis de los determinantes de costos demuestra la importancia del compromiso, experiencia, calidad, tecnología, modelo de gestión, alcance, escala y factores institucionales en los costos de la organización.

Palabras clave: Fondos de Pensión. Cadena de Valor. Posicionamiento Estratégico. Determinantes de Costos.

Brenda de Borba Trajano ${ }^{1}$

Larissa Marx Welter ${ }^{2}$ Ângela Rozane Leal de Souza ${ }^{3}$

Paulo Schmidt ${ }^{4}$

\footnotetext{
1 Mestranda do Programa de Pós-Graduação em Controladoria e Contabilidade da Universidade Federal do Rio Grande do Sul - PPGCONT/UFRGS. Brasil. E-mail: brendaborbatrajano@gmail.com

${ }^{2}$ Mestranda do Programa de Pós-Graduação em Controladoria e Contabilidade da Universidade Federal do Rio Grande do Sul - PPGCONT/UFRGS. Brasil. E-mail: larissamarxwelter@gmail.com

3 Doutora em Agronegócios pela Universidade Federal do Rio Grande do Sul - UFRGS. Professora da Universidade Federal do Rio Grande do Sul - UFRGS. Brasil. E-mail: angela.souza@ufrgs.br

${ }^{4}$ Doutor em Controladoria e Contabilidade pela Universidade de São Paulo - USP. Professor da Universidade Federal do Rio Grande do Sul - UFRGS. Brasil. E-mail: pschmidt@ufrgs.br
} 


\section{INTRODUÇÃO}

$\mathrm{O}$ mercado competitivo abrange um vasto conjunto de estudos que interliga o meio acadêmico com a gestão de negócios. Diante da concentração de empresas disputando mercado entre si, faz-se necessário, cada vez mais, a elaboração de estratégias perspicazes perante a concorrência acirrada. Porter (1993) já enfatizava que para administrar todo o sistema de uma empresa com competência é fundamental dar atenção para a vantagem competitiva, criando, assim, um diferencial com relação aos concorrentes.

Shank e Govindarajan (1997) definem a Gestão Estratégica de Custos como uma análise de custos vista de um contexto no qual os elementos estratégicos se tornam mais conscientes. Os autores definem três pilares da GEC: a) análise da cadeia de valor; b) análise do posicionamento estratégico; c) análise de direcionadores de custos (Fullerton, Kennedy, \&Widener, 2014; Hald \&Thran, 2016; Malmia, 2016).

Porter (1993) salienta que a cadeia de valores deve ser analisada como um sistema, e não uma administração de partes separadas, para que, assim, se alcance a vantagem competitiva. A relevância da análise da cadeia de valor esteve presente em diversos estudos (Vesco, Tarifa, Pacheco, \&Dall'Asta; 2014; Mol, 2015; El-Sayed,Dickson,\& El-Naggar, 2015; Amara,Halilem, \&Traoré, 2016).

Dada a importância desta análise, os estudos de El-Sayed, Dickson e El-Naggar (2015) realizaram a análise de uma cadeia de valor no setor de hidrocultura do Egito, evidenciando uma cadeia simples, que se trata de fornecedores de insumos alimentares, fabricantes de produtos aquáticos, comerciantes e piscicultores. Hald e Thran (2016) realizaram a análise de como a estratégia da cadeia de valor e a contabilidade gerencial estão relacionadas, além de verificarem como a estrutura da cadeia de valor modifica essa relação, propondo estratégias enxutas e ágeis para adaptação de ambos os conceitos.O segundo pilar da GEC, a análise do posicionamento estratégico, foi abordado no estudo de Cavalcanti, Ferreira e Araujo (2013), com a proposta de investigar a integração existente entre este e a gestão de custos de uma empresa beneficiadora de aço inox, no qual concluíram que o sistema de custeio se apresentava ineficiente, prejudicando a gestão estratégica de custos. Seguindo a mesma linha, Creptureanu (2016) investigou a intensidade da concorrência e sua influência na posição estratégica do mercado.

Já o terceiro pilar foi destacado por Costa (2011) que se propôs a identificar os elementos caracterizadores dos fatores determinantes de custos nas empresas produtoras do setor de eletroeletrônicos no Brasil. Os resultados, apesar de não totalmente conclusivos, indicaram uma tendência para o setor estudado.

Diante desta exposição, o presente estudo busca a resposta para o seguinte questionamento: De que maneira são gerenciados a Cadeia de Valor, o Posicionamento Estratégico e os Cost Drivers de uma Entidade Fechada de Previdência Complementar brasileira? Com base nesta problemática, elaborou-se como objetivo identificar como são gerenciados a Cadeia de Valor, o Posicionamento Estratégico e os Cost Drivers em uma Entidade Fechada de Previdência Complementar do Brasil, adaptando as diretrizes originalmente propostas por Shank e Govindarajan (1997) e Costa (2011).

Uma das justificativas desta pesquisa se encontra em entender como as variáveis estudadas são importantes para a eficácia da gestão em Entidades Fechadas de Previdência Complementar. Estas entidades, também conhecidas como Fundos de Pensão, são responsáveis pelo pagamento de aposentadorias e pensões de forma complementar aos benefícios concedidos pelo Regime Geral de Previdência Social, para grupos específicos de trabalhadores com um mesmo vínculo empregatício ou as sociativo.

Ainda, segundo a Associação Brasileira das Entidades Fechadas de Previdência Complementar (ABRAPP) (2017), mesmo sendo entidades sem fins lucrativos, os Fundos de Pensão buscam retorno financeiro positivo para seus participantes, e possuem, em conjunto, um patrimônio que representa $12,9 \%$ do Produto Interno Bruto do Brasil. Diante da representatividade do setor aliada às incertezas da aposentaria, que por hora perduram, se faz importante estudos voltados aos Fundos de Pensão, indiretamente afetados pela reforma proposta, que se apresentam como uma oportunidade atrativa para a população por eles amparada. Assim, infere-se que o estudo dos componentes essenciais para a gestão estratégica dos Fundos de Pensão, contribui de maneira relevante para a literatura relacionada a estas entidades e, também, ao gerenciamento e estratégica.

O presente artigo contempla, além desta introdução, o referencial teórico, abordando os conceitos pertinentes à Gestão Estratégica de Custos e as características de um Fundo de Pensão. Posteriormente, na seção três, foram caracterizados os procedimentos metodológicos utilizados, enquanto na seção quatro são apresentados os resultados e discussões. Por fim, é explanada a conclusão da pesquisa, em comparação com os demais estudos referenciados.

\section{REFERENCIAL TEÓRICO}

\subsection{Gestão Estratégica de Custos}

A Gestão Estratégica de Custos (GEC) é uma 
estrutura analítica que visa alcançar a vantagem competitiva sustentável de uma empresa, relacionando a estratégia gerencial da organização com suas informações contábeis relevantes (Shank \& Govindarajan, 1997). Segundo esses autores, a Gestão Estratégica de Custos (GEC) é formada por três pilares: a análise da Cadeia de Valor, a análise do Posicionamento Estratégico e a análise dos Cost Drivres.

Em estudos relacionados, Souza, Guerra, Lara, Avelar e Amorin (2009) buscaram apresentar os possíveis benefícios de desenvolver a GEC em organizações hospitalares e analisar se as organizações hospitalares brasileiras desenvolvem GEC. Como resultado, identificaram que as organizações pesquisadas não desenvolvem efetivamente uma GEC, e somente um dos hospitais estudados apresenta mais indícios de preocupação por parte dos gestores com a gestão de custos no longo prazo.

Souza, Silva e Pilz (2010), por sua vez, procuraram identificar quais formatações e práticas da GEC estão presentes na gestão empresarial. A partir do estudo realizado, eles evidenciaram que há acentuada preferência pelo uso de tradicionais práticas de gestão de custos, apesar do perfil da empresa pesquisada em atuar com liderança em mercados competitivos.

Ademais, Raupp, Borgert, Nunes e Ferrari (2012) investigaram a aderência do modelo de GEC implementado em uma empresa estatal de energia elétrica ao modelo proposto por Shank e Govindarajan. O modelo de GEC foi implementado parcialmente na Empresa e houve certo consenso entre os entrevistados de que: i) a análise da cadeia de valor concentra fatores que facilitam e outros que dificultam a implantação do modelo; ii) a análise do posicionamento estratégico concentra os fatores que estão mais estruturados; e iii) a análise dos direcionadores de custos concentra os fatores que mais dificultam a completa implementação da GEC.

\subsubsection{Cadeia de valor}

A Cadeia de Valor, segundo Shank e Govindarajan (1997), é o conjunto de atividades geradoras de valor ao produto ou serviço entregue ao consumidor final, em um contexto global, incluindo as atividades externas à empresa. Os autores afirmamque a empresa é parte de uma cadeia de atividades que geram valor ao seu produto ou serviço. Nesse sentido, ao analisar a Cadeia de Valor, os gestores têm a possibilidade de explorar,além das atividades internas efetuadas pela empresa, as ligações com seus fornecedores e clientes (Shank \& Govindarajan, 1997).A Figura 1 apresenta um modelo de Cadeia de Valor.

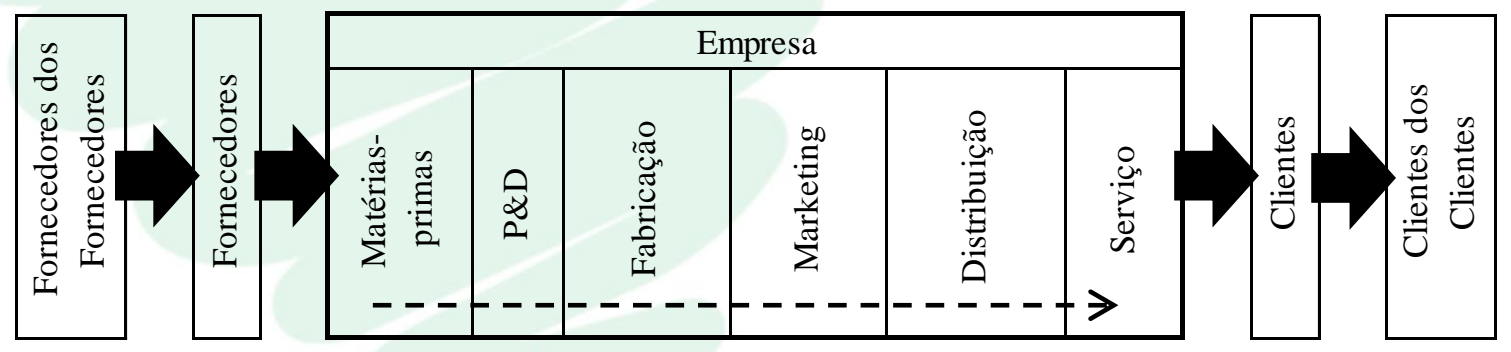

Figura 1 - Modelo de Cadeia de Valor

Nota.Fonte: adaptado de Shank e Govindarajan (1997).

Outro conceito de Cadeia de Valor é definido por Rocha e Borinelli (2007), que afirmam que a "Cadeia de Valor é uma sequência de atividades que se inicia com a origem dos recursos e vai até o descarte do produto pelo último consumidor.”. Os autores definem, ainda, que a sua finalidade é de subsidiar a gestão estratégica, por permitir o entendimento e a tomada de decisão sobre os aspectos econômico, financeiro, operacional e patrimonial das atividades e do sistema de geração de valor como um todo.

Para construir a Cadeia de Valor, é necessário reconhecer quais atividades que geram valor ao produto ou serviço. Porter (1989) classifica as atividades de valor em duas categorias: as atividades primárias e as atividades de apoio. As atividades primárias são diretamente relacionadas à produção, venda e transferência do produto ou serviço, enquanto as atividades de apoio servem de suporte para as atividades primárias, fornecendo tecnologia, recursos humanos, infraestrutura, entre outros (Porter, 1989).

Tanto as atividades primárias quando as atividades de apoio são interdependentes entre si, e o relacionamento entre as atividades de valor forma um elo entre elas, que é o impacto entre a forma que uma atividade é executada e o reflexo, por consequência, no custo ou desempenho de outra (Porter, 1989). Realizar a otimização e a coordenação dos elos pode gerar vantagem competitiva para a empresa, pois, ao analisar as relações entre as atividades e identificar aquelas que possuem descasamento (tradeoff), elos podem ser otimizados para a obtenção de um mesmo resultado global (Porter, 1989).

Destacam-se, ainda, outros estudos, que também foram desenvolvidos sobre a temática de análise da Cadeia de Valor, de abrangência nacional e internacional. Vesco et al. (2014) analisaram sob o 
contexto estratégico a cadeia de valores na gestão de custos em cooperativas agropecuárias do Estado do Paraná.A ligação entre as diferentes atividades das cooperativas agropecuárias inicia-se na aquisição das matérias-primas, até a manutenção pós-vendas dos produtos por estas desenvolvidos.

Mol (2015) investigou os novos desafios para a transparência da cadeia de valor e suas consequências. A transparência na cadeia de valor está ligada a conotação positiva de que quanto maior a transparência, melhor será a sustentabilidade da cadeia e o empoderamento dos consumidores e da sociedade civil.

El-Sayed, Dickson e El-Naggar (2015) avaliaram o desempenho da cadeia de valor do setor de alimentos para a aquicultura no Egito, em termos de adição de valor, emprego e rentabilidade. A cadeia de valor da hidrocultura egípcia é relativamente simples, incluindo quatro grupos principais de partes interessadas: fornecedores de insumos alimentares, produtores de produtos aquáticos, comerciantes e piscicultores.

E Amara, Halilem e Traoré (2016), por sua vez, avaliaram até que ponto os professores das escolas de negócios criam valor para as empresas. Em torno de $74 \%$ dos acadêmicos de negócios oferecem serviços de valor agregado e assessoria especializada para empresas em um raio de $100 \mathrm{~km}$. Uma minoria de acadêmicos oferece soluções personalizadas para empresas e desenvolve estratégias explícitas para competir com empresas de consultoria e outros estudiosos.

\subsubsection{Posicionamento estratégico}

O segundo tema chave para a Gestão Estratégica de Custos faz referência ao uso da informação na contabilidade Gerencial (Shank \& Govindarajan, 1997). Os autores trazem como questionamento norteador qual seria o papel desempenhado pela gestão de custos na empresa. A resposta deste questionamento irá ditar o tipo de estratégia definida pelo negócio.

A maneira pela qual a entidade irá guiar seu caminho é que a colocará em vantagem perante as demais concorrentes. Para Porter (1993), a vantagem competitiva trata do êxito da empresa com relação às suas concorrentes, ou seja, quais características que lhe trazem benefícios perante as demais.

Desta forma, para atingir a vantagem competitiva, Porter (1989), propõe três estratégias básicas: a) liderança de custos; b) diferenciação do produto; e c) enfoque. A primeira delas, o baixo custo, é explicada por Shank e Govindarajan (1997): “[...] o foco principal desta estratégia é obter um baixo custo em relação aos concorrentes.”. Já a diferenciação, segundo os autores, baseia-se em fornecer ao cliente um produto como sendo único, englobando abordagens de fidelidade à marca, serviço especializado ao cliente, rede de revendedores e/ou tecnologia de produto.

Porter (1989) ainda aborda o enfoque como estratégia, destacando esta como bastante diferenciada. Segundo o autor, o enfocador escolhe um segmento e adapta sua estratégia para atendê-lo e, também, o enfoque possuiduas variantes, que pode ser de enfoque no custo ou enfoque na diferenciação. Destaca-se, então, a importância do posicionamento estratégico da empresa, que irá refletir no gerenciamento, principalmente com relação às mudanças de mercado, que possam interferir diretamente na sua posição (Cavalcanti, Ferreira, \& Araujo, 2013).

Relacionado a presente pesquisa, o estudo de Cavalcanti, Ferreira e Araujo (2013) investigou a integração existente entre o posicionamento estratégico e a gestão de custos de uma empresa beneficiadora de aço inox. Como resultado, identificaram que $\mathrm{O}$ sistema de custeio utilizado pela empresa é ineficiente comprometendo a implantação de uma gestão estratégica baseada em informações de custos que the proporcione uma vantagem competitiva.

Silva Filho, Carneiro, \& Ferreira (2013) investigaram se as empresas petrolíferas multinacionais adotaram posicionamento estratégico distinto e se este e o desempenho da empresa estão relacionados. Não houve diferenças estatisticamente significativas no desempenho futuro anual esperado. Houve diferenças no desempenho passado entre os tipos estratégicos em cinco dos oito anos do estudo. Além disso, evidenciaram que a estabilidade na posição estratégica para um longo período de tempo está associada a um melhor desempenho.

Krielow e Santos (2014) buscaram entender o processo de definição do posicionamento estratégico, partir do desenvolvimento de competências organizacionais em uma empresa do segmento médico hospitalar. Observaram que as competências organizacionais se desenvolvem a partir de um plano previamente definido, que ao longo do tempo se estabelece a partir dos recursos e características do negócio, consolidando o posicionamento estratégico.

E, ainda neste contexto, Piran, Nunes, Souza e Nunes (2016) analisaram como a gestão de custos apoia a integração entre posicionamento estratégico e estratégia de manufatura, em uma subsidiária brasileira de uma empresa alemã, que atua no segmento metal mecânico. Identificaram que a empresa compete na estratégia de diferenciação na sua principal linha de produtos, porém existe forte competição por liderança de custos entre as subsidiárias da organização, o que sugere características da estratégia híbrida. A empresa adotou a estratégia de manufatura enxuta e fábricas focalizadas, utilizando a gestão de custos como principal ferramenta para gestão.

\subsubsection{Cost drivers}

Definida a Cadeia de Valor e o Posicionamento Estratégico, o terceiro ponto da Gestão Estratégica de Custos diz respeito aos Cost Drivers, 
que Shank e Govindarajan (1997) traduzem como Direcionadores de Custos. Já outros autores, como Costa (2011), referem-se ao termo como Determinantes de Custos, e não direcionadores. Este viés parte do princípio de que a tradução da obra de Porter (1993) sofreu diferentes interpretações.

Destaca-se que a literatura dos direcionadores de custos é mais difundida do que a dos determinantes (Catânio, Santos, \& Abbas, 2015), no entanto, é importante conhecer os conceitos para, assim, adaptálos à base conceitual dos Cost Drivers. Para Shank e Govindarajan (1997) é necessário se questionar qual a variável que melhor explica a mudança no custo por unidade. A influência causada por este "direcionador", muitas vezes atribuída ao volume de produção, irá impactar diretamente o custo do produto.

Seguindo por outra linha de raciocínio, Costa e Carneiro (2014, p.4) entendem que "Os determinantes de custos são as causas reais dos custos. Em outras palavras, a raiz dos custos, ou ainda, os elementos que estão no cerne e provocam a existência de um determinado custo, sua essência.". Ainda reforçam que os determinantes são "fatores que determinam a magnitude dos parâmetros da função custo de uma organização [...]" (Costa \& Carneiro, 2014, p.4). Para fins de melhor adaptação ao objeto do presente estudo, foram considerados os determinantes de custos propostos por Costa (2011), relacionados no 0 .

\begin{tabular}{|c|c|}
\hline Cost Drivers & Descrição \\
\hline 1. Modelo de gestão & Regras de conduta organizacional. \\
\hline 2. Escala & Fator de dimensão ou porte da empresa. \\
\hline 3. Utilização da capacidade & Volume e nível de ociosidade. \\
\hline 4. Escopo & Utilização de recursos comuns para a criação de múltiplos produtos. \\
\hline 5. Experiência & Horizonte de tempo de desempenho da atividade. \\
\hline 6. Tecnologia & Forma de utilização de conhecimento para a atividade fim. \\
\hline $\begin{array}{l}\text { 7. Diversidade de produtos e } \\
\text { serviços }\end{array}$ & Variedade ou amplitude de produtos e serviços ofertados. \\
\hline 8. Diversidade de fornecedores & Variedade ou amplitude de fornecedores das matérias-primas. \\
\hline 9. Diversidade de clientes & Variedade ou amplitude do público-alvo. \\
\hline $\begin{array}{l}\text { 10. Diversidade de máquinas e } \\
\text { equipamentos }\end{array}$ & Variedade ou amplitude do maquinário para a produção. \\
\hline 11. Comprometimento & Compromisso dos colaboradores comas questões ligadas à empresa. \\
\hline 12. Qualidade & $\begin{array}{l}\text { Características que levam o cliente a optar pelo produto/serviço em } \\
\text { detrimento a outros. }\end{array}$ \\
\hline 13. Arranjo físico & Local adequado para o acondicionamento dos produtos. \\
\hline 14. Projeto de produto/serviço & $\begin{array}{l}\text { Desenho do produto/serviço para atender as necessidades e demandas do } \\
\text { cliente. }\end{array}$ \\
\hline 15. Relações na cadeia de valor & $\begin{array}{l}\text { Relação entre os agentes, internos ou externos, que visam um benefício } \\
\text { comum. }\end{array}$ \\
\hline 16. Estrutura de capitais & Forma de financiamento da empresa - recursos próprios e de terceiros. \\
\hline 17. Tempestividade & Fator de aumento ou diminuição dos custos em relação aos concorrentes. \\
\hline 18. Localização & Variável estratégica cuja escolha afeta os custos. \\
\hline 19. Fatores institucionais & $\begin{array}{l}\text { Normas e regulamentações que possam afetar a operação da empresa e, } \\
\text { consequentemente, seus custos. }\end{array}$ \\
\hline
\end{tabular}

Quadro 1 - Classificação dos Cost Drivers

Nota.Fonte: adaptado de Costa (2011). 
Esta proposta de classificação dos determinantes de custos foi elaborada a partir da literatura e não é considerada definitiva (Costa, 2011). A partir dela, serão contemplados no presente estudo os determinantes que se fizerem prudentes na análise em questão, em virtude de ser um estudo mais recente diante dos demais sobre o tema.

Outros estudos já realizados estão relacionados a esta pesquisa. $\mathrm{O}$ estudo de Terpstra e Verbeeten (2014), por exemplo, buscou investigar a relação entre satisfação do cliente, custos de serviço e valor do cliente em uma empresa de serviços financeiros. Observaram que a satisfação do cliente é um determinante de valor, no entanto, essa satisfação não é livre de custos e deve-se considerar tais custos, bem como os benefícios, de aumentar a satisfação do cliente.

Costa e Carneiro (2014) procuraram esclarecer o conceito e fatores da taxonomia dos determinantes de custos, verificando a viabilidade de classificações, hierarquizações ou agrupamentos. Os determinantes mais comumente aceitos pela teoria podem ser considerados como parte de sua taxonomia. Foi sugerido pelos autores o agrupamento dos determinantes em: (a) relacionados aos produtos/serviços; (b) relacionados ao processo, e; (c) globais.

Catânio, Santos e Abbas (2015) realizaram uma análise crítica das definições, dos conceitos, dos aspectos utilitaristas e da aplicabilidade, considerando os frameworks do ABC e da GEC que utilizam a expressão cost drivers. Como resultado, apresentaram os vieses encontrados na literatura nacional e contribuíram por meio de críticas às definições e conceitos, apresentando, ainda, uma proposta conceitual para os cost drivers abordando suas características.

Há, ainda, o estudo de Carneiro, Duarte e Costa (2015) que buscou identificar os principais fatores determinantes dos custos da soja, buscando avaliar aqueles que são mais relevantes e seus principais efeitos sobre a estrutura de custos das organizações. Foi verificada a atuação dos principais fatores determinantes de custos, como localização, escala e utilização da capacidade, tecnologia, experiência e aprendizagem, tempestividade, relações na cadeia de valor, estrutura de capitais e fatores institucionais. Esses fatores modificam a estrutura de custos dos produtores e implicam diferenças significativas nos custos de cada região em diferentes períodos.

\subsection{Previdência Complementar Fechada}

No Brasil, a previdência é composta por três pilares: o Regime Geral de Previdência Social (RGPS), os Regimes Próprios de Previdência dos Servidores Públicos (RPPS) e o Regime de Previdência Complementar. A Previdência Complementar é facultativa, como objetivo de oferecer ao trabalhador cobertura previdenciária suplementar, sendo composta por dois grupos distintos, formados pelas Entidades Abertas de Previdência Complementar (EAPC) e pelas Entidades Fechadas de Previdência Complementar (EFPC) (BRASIL, 2008). A Figura 2 apresenta a estrutura atual que compõe o sistema da previdência do Brasil.

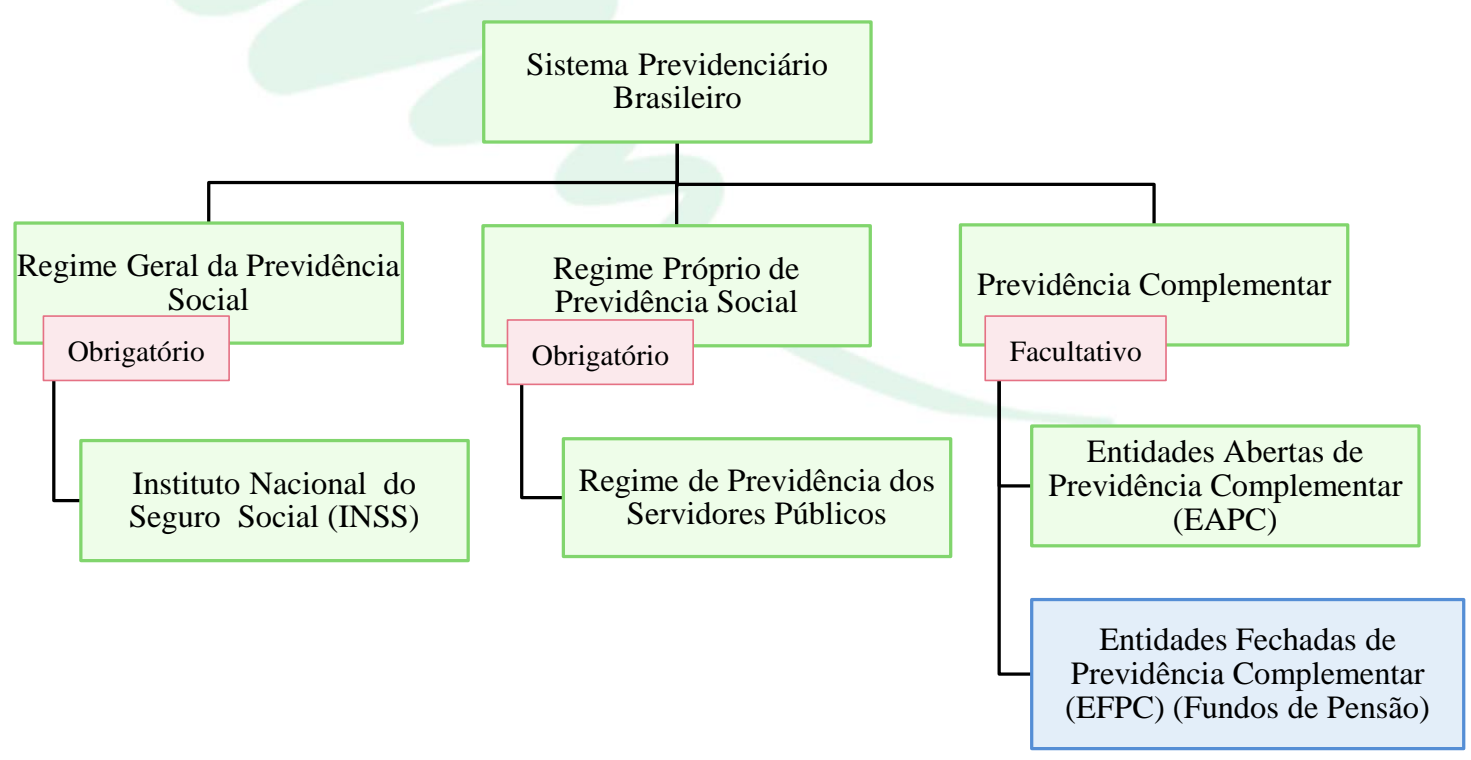

Figura 2 - Estrutura do sistema previdenciário brasileiro

Nota.Fonte: elaborado a partir de Ministério da Previdência Social, Brasil (2008). 
No último quadrante da Figura 2, tem-se as Entidades Fechadas de Previdência Complementar (EFPC), mais conhecidas como Fundos de Pensão, são instituições sem fins lucrativos, constituídas em conformidade ao disposto na Lei Complementar $\mathrm{n}^{\circ}$ 109, de 29 de maio de 2001, com o objetivo de administrar planos de benefícios de caráter previdenciário para grupos específicos de trabalhadores, vinculados a empregadores (denominados Patrocinadores), ou a entidades de classe (denominados Instituidores) (Brasil, 2001; Silva, 2003). Desde sua origem, os Fundos de Pensão objetivam: garantir a estabilidade financeira de seus participantes por meio do pagamento de aposentadorias e pensões.

A estrutura mínima necessária para o funcionamento de um Fundo de Pensão é composta por um Conselho Deliberativo (órgão colegiado representativo que delibera as diretrizes da entidade), um Conselho Fiscal (órgão responsável pela fiscalização e controle interno das atividades) e uma Diretoria Executiva (órgão responsável pela administração financeira e patrimonial). Atualmente, o Conselho Nacional de Previdência Complementar (CNPC) é o órgão que regula o setor de previdência complementar. Além disso, a Superintendência Nacional de
Previdência Complementar (PREVIC) é a entidade autárquica vinculada ao Ministério da Fazenda, que fiscaliza e supervisiona os Fundos de Pensão e executa políticas para o Regime de Previdência Complementar (Brasil, 2008).

Para atender às necessidades dos participantes, é estipulado um conjunto de regras, direitos e obrigações, denominado Plano de Benefícios. Em geral, os benefícios básicos de umplano de previdência são Aposentadoria Normal, Aposentadoria por invalidez e Pensão por Morte. Os planos de benefícios são classificados em três modalidades: Benefício Definido (benefício previamente definido), Contribuição Definida (benefício varia conforme nível de contribuição) e Contribuição Variável (combinação de fatores das duas modalidades anteriores) (Caetano, 2014).

Atualmente, existem no Brasil 307 Fundos de Pensãoque administram, ao total, 1.104 planos de benefícios (Previc, 2017). Em março de 2017, o patrimônio total destas Entidades Fechadas de Previdência Complementar (EFPC) resultou em uma quantia equivalente a 12,9\% do PIB do país (Abrapp, 2017). O Quadro 2 apresenta as principais informações do setor de previdência complementar fechada no Brasil.

\begin{tabular}{|c|c|c|}
\hline Descrição & Total & Dados por categorias \\
\hline $\begin{array}{lr}\text { Quantidade } & \text { de } \\
\text { empresas/instituições } & \text { ligadas } \\
\text { aos Fundos de Pensão }\end{array}$ & $\begin{array}{c}\text { Total de } \\
3.195 \\
\text { empresas }\end{array}$ & $\begin{array}{l}2.193 \text { patrocinadores privados } \\
507 \text { patrocinadores públicos } \\
495 \text { instituidores }\end{array}$ \\
\hline $\begin{array}{l}\text { Quantidade de Planos de } \\
\text { Benefícios administrados } \\
\text { pelos Fundos de Pensão por } \\
\text { modalidade }\end{array}$ & $\begin{array}{l}\text { Total de } \\
1.104 \\
\text { Planos de } \\
\text { Benefícios }\end{array}$ & $\begin{array}{l}323(29 \%) \text { planos de Benefício Definido } \\
\text { Essa modalidade apresentou queda ao longo do tempo, já que em } \\
\text { sua maioriasão planos fechados para adesão de novos } \\
\text { participantes. } \\
422(38 \%) \text { planos de Contribuição Definida } \\
359(33 \%) \text { planos de Contribuição Variável }\end{array}$ \\
\hline $\begin{array}{l}\text { Recursos Garantidores dos } \\
\text { Fundos de Pensão para a } \\
\text { cobertura dos benefícios }\end{array}$ & $\begin{array}{l}\text { Total de } \\
\text { R } \$ 773 \\
\text { bilhões }\end{array}$ & $\begin{array}{l}\text { R\$ } 461 \text { bilhões em Entidades de patrocínio público predominante } \\
\text { R\$ } 305 \text { bilhões em Entidades de patrocínio privado predominante } \\
\text { R\$ } 7 \text { bilhões em Fundos de Pensão Instituídos }\end{array}$ \\
\hline $\begin{array}{l}\text { Estimativa de participantes } \\
\text { dos planos de benefícios }\end{array}$ & $\begin{array}{l}\text { Total de } \\
7.269 \\
\text { milhões }\end{array}$ & $\begin{array}{l}2.560 \text { milhões }(35 \%) \text { de participantes em atividade } \\
753 \text { milhões }(10 \%) \text { de participantes as sistidos } \\
3.956 \text { milhões }(55 \%) \text { de dependentes }\end{array}$ \\
\hline
\end{tabular}

Quadro 2 - Informações gerais do setor de previdência complementar fechada Nota. Fonte: adaptado de PREVIC (2017) e ABRAPP (2017).

Observando, nos quantitativos anteriormente descritos no Quadro 2, o volume e expressividade no âmbito econômico e social da previdência complementar fechada, destaca-se a importância deste setor.Assim sendo, o gerenciamento dos custos e da visão estratégica por parte dos gestores dos Fundos de Pensão, mostra-se como uma medida na busca pela continuidade da organização e pelo cumprimento de suas obrigações no longo prazo.

\section{MÉTODO}

A presente pesquisa é classificada como qualitativa, quanto à abordagem do problema, e descritiva, quanto aos seus objetivos. A abordagem é qualitativa, pois o estudo é relativo à qualidade do fenômeno, tendo em vista descrição, compreensão e interpretação dos acontecimentos, por meio do contato direto e prolongado com o ambiente estudado, não 
utilizando de forma determinante a quantificação em sua abordagem (Martins \& Theóphilo, 2009). É descritiva porque tem como objetivo descrever as características do fenômeno estudado, além de identificar as relações entre ele e determinadas variáveis existentes no contexto de análise (Gil, 2008).

Para o desenvolvimento da pesquisa, foi realizado um estudo de caso único em um Fundo de Pensão brasileiro. A entidade possui perfil II (médio) conforme classificação de porte, complexidade e riscos estabelecida pela Previc (2016). Segundo Yin (2015), o estudo de caso é definido por dois as pectos distintos: primeiro, por ser um método que investiga empiricamente e em profundidade um fenômeno contemporâneo no contexto em que está inserido; e, segundo, por não ser possível determinar os limites entre o fenômeno e o seu contexto. Gil (2008) argumenta que a qualidade de informações colhidas através do estudo de caso, estão relacionadas à utilização de múltiplas fontes de evidência, também conhecida como triangulação de dados. A triangulação realizada neste estudo, através de um protocolo de estudo de caso, foi composta das seguintes técnicas de coleta de dados: entrevista, documentação e observação.

Inicialmente foram realizadas entrevistas semiestruturadas com os colaboradores citados no 0 , bem como a observação do ambiente interno efetuada na sede da entidade. A coleta de dados também foi realizada por meio de análise documental: (a) indireta em regulamentos, estatutos, relatórios anuais, demonstrações atuariais, balancetes mensais, entre outros; e, (b) direta - a partir de documentos visualizados diretamente na entidade, como a relação de fornecedores descrita pela gerente de benefícios. Os dados foram coletados durante o segundo trimestre de 2017. O Quadro 3 apresenta uma breve caracterização dos perfis dos colaboradores entrevistados.

\begin{tabular}{|c|c|c|c|c|}
\hline Descrição & Departamento & Cargo & Escolaridade & Tempo de Empresa \\
\hline Entrevistado A & $\begin{array}{c}\text { Investimentos e } \\
\text { Financeiro }\end{array}$ & $\begin{array}{c}\text { Diretor Financeiro } \\
\text { e de Investimentos }\end{array}$ & Graduação em Economia & 2 anos \\
\hline Entrevistado B & $\begin{array}{c}\text { Administrativo e } \\
\text { de Previdência }\end{array}$ & $\begin{array}{c}\text { Responsável pela } \\
\text { área de Benefícios }\end{array}$ & Graduação em História & 31 anos \\
\hline Entrevistado C & $\begin{array}{c}\text { Administrativo e } \\
\text { de Previdência }\end{array}$ & $\begin{array}{c}\text { Administrativo e } \\
\text { de Previdência }\end{array}$ & $\begin{array}{c}\text { Graduação em Ciências } \\
\text { Etuaris e Mestrado em } \\
\text { Economia }\end{array}$ & 30 anos \\
\hline Entrevistado D & Contabilidade & Contador & $\begin{array}{c}\text { Graduação em Ciências } \\
\text { Contábeis e Especialização } \\
\text { em Controladoria }\end{array}$ & 2 anos \\
\hline
\end{tabular}

Quadro 3 - Perfil dos entrevistados

Fonte: dados obtidos na pesquisa (2017).

Objetivando manter o rigor metodológico necessário em uma pesquisa científica, foi elaborado o protocolo de estudo de caso para auxiliar na coleta de dados, de acordo com o modelo proposto por Guerra (2010). O principal instrumento de coleta de dados foi a entrevista. Para proceder esta coleta, foi elaborado o roteiro de entrevista, que foi submetido à validação de um pesquisador da área, e suas contribuições resultaram no aperfeiçoamento de 12 das 21 questões formuladas.

A coleta de dados foi realizada durante o mês de julho de 2017, em duas visitas semanais na sede do Fundo de Pensão. Após a coleta de dados, foi realizada a triangulação dos dados coletados por cada um dos instrumentos (entrevista, observação e documentação), convergindo às diversas fontes de evidência, a fim de corroborar os resultados obtidos (Martins \& Theóphilo, 2009).

\section{RESULTADOS}

Por meio do estudo de caso realizado, os resultados apresentados sucedem à uma inicial caracterização da entidade e posterior análise dos três pilares da Gestão Estratégica de Custos.

\subsection{Caracterização da Entidade}

O estudo foi realizado em uma Entidade Fechada de Previdência Complementar que atua há cerca de 40 anos no setor de previdência complementar, com aproximadamente 10 colaboradores em seu quadro de pessoal interno, além da Diretoria e dos Conselhos Deliberativo e Fiscal. O Fundo de Pensão administra dois planos de benefícios aos seus participantes, um plano em extinção, estruturado na modalidade de Benefício Definido (denominado neste estudo como Plano 1), e o outro estruturado como Contribuição Variável, aberto para 
novas adesões (denominado neste estudo como Plano 2).

No encerramento do exercício de 2016, os dois planos de benefícios apresentaram resultado superavitário, demonstrando a suficiência do Patrimônio de Cobertura em relação às Provisões Matemáticas (montante de obrigação futura com o pagamento de benefícios dos atuais e futuros assistidos). $\mathrm{O}$ atuário responsável pelas Provisões Matemáticas, custeio previdencial e apuração do equilíbrio técnico de ambos os planos, não faz parte do corpo de colaboradores da entidade, sendo contratado por meio da consultoria atuarial.

O Plano 1, mais antigo da Entidade, criado na década de 1970, possui um montante próximo a $\mathrm{R} \$ 750$ milhões de Provisões Matemáticas e uma população com idade média de mais de 60 anos de idade. Já o Plano 2, fundado 20 anos após o primeiro, possui um grupo com idade média de 40 anos, aproximadamente. Por ser um plano mais novo, cujos participantes, em sua grande maioria, estão em fase de acumulação de recursos, o montante de Provisões Matemáticas do segundo plano encontra-se em um patamar menor ao do primeiro, com cerca de R\$ 65 milhões.

\subsection{Análise da Cadeia de Valor}

A cadeia de valor designa uma série de atividades relacionadas e desenvolvidas pela empresa a fim de satisfazer as necessidades dos clientes, desde as relações com os fornecedores e ciclos de produção e venda até a fase da distribuição para o consumidor final. Neste contexto, cada elo da cadeia de atividades está interligado.

A Cadeia de Valor é formada por uma sucessão de elos que acabam por gerar valor ao cliente final. Os elos centrais da Cadeia de Valor do Fundo de Pensão em análise estão diretamente relacionados às atividades primárias da organização, que se iniciam na captação de novas adesões, e se encerram na concessão de benefícios aos participantes (ativos, aposentados ou pensionistas), considerados como os clientes dos serviços prestados pela entidade.

Os planos oferecem um rol de benefícios aos seus participantes, que abrange auxílio-doença aos participantes em atividade, aposentadoria normal, aposentadoria por invalidez e, aos dependentes, pensão por morte do titular do plano. A 0 apresenta a estrutura central da Cadeia de Valor da entidade.

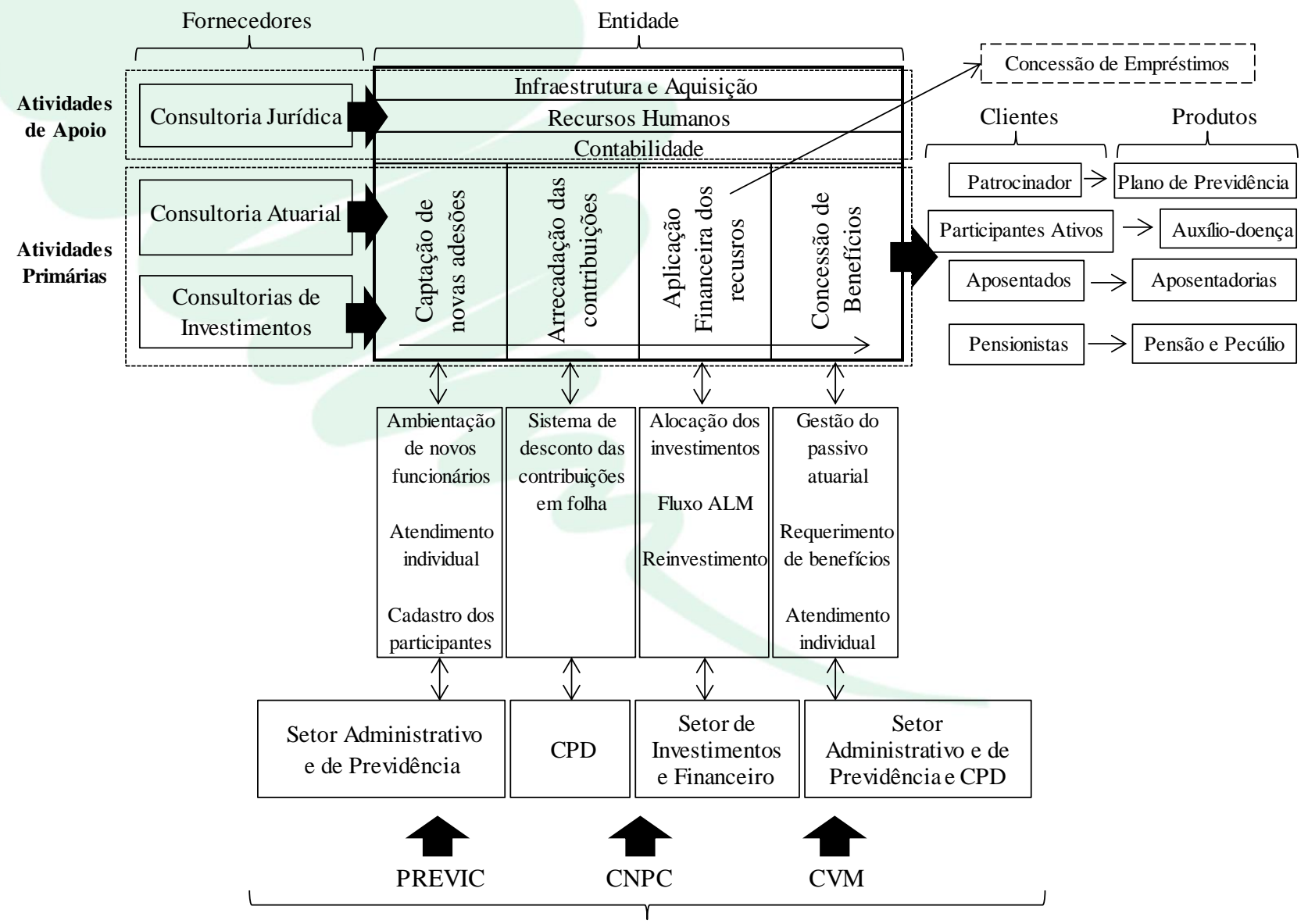

Fatores Institucionais

Figura 3 - Cadeia de valor da entidade

Nota.Fonte: dados obtidos na pesquisa (2017). 
Segundo o Entrevistado E, para entregar um bom produto aos clientes, todos os setores são fundamentais, mas há um tripé que sustenta as atividades da fundação, qual seja: atuarial (Administrativo e Previdência), financeiro (Investimentos e Financeiro) e informática (Centro de Processamento de Dados). O entrevistado complementa, ainda:"não consigo imaginar a fundação sem um desses três pilares, porque um depende do outro [...] não vejo nem mais nem menos importância de uma para a outra, elas são complementares"(Entrevistado E, 2017).

Outro ponto importante quanto aos custos é a folha salarial dos colaboradores. Em 2016, 75,7\% das despesas administrativas foram utilizadas para 0 pagamento de pessoal e encargos, sendo 52,8\% de gastos com pessoal próprio. Segundo o Entrevistado C, a entidade está passando por um processo gradual de substituição dos funcionários de carreira antiga por colaboradores de carreira nova, principalmente em razão das aposentadorias dos funcionários antigos. $\mathrm{O}$ mesmo entrevistado informou que essa substituição gradual resulta em aproximadamente $35 \%$ de redução, apurado por meio de estudo, do custo com a folha salarial no médio prazo.

Observou-se que fundação possui fornecedores estratégicos, que fazem parte da cadeia de valor da fundação, em duas áreas: na área de investimentos e na área atuarial. $O$ fornecedor de serviços atuariais representa aproximadamente $7 \%$ dos gastos do primeiro trimestre de 2017. Já os fornecedores de serviços para a área de investimentos representaram, em conjunto, representa $7,7 \%$ dos gastos da entidade no primeiro trimestre de 2017.Logo, os fornecedores estratégicos para a geração de valor dos serviços da organização representam em torno de $14,7 \%$ dos gastos da fundação.

Além disso, gastos pontuais ocorreram entre 2016 e 2017, com serviços de fornecedores relacionados à Cadeia de Valor da entidade. Um deles foi a atualização da marca e do site da entidade, representando cerca de $7 \%$ dos gastos com terceiros no anode 2016. O outro gasto pontual ocorreu em virtude da contratação de serviços de sistema de informação vinculados ao Centro de Processamento de Dados (CPD), que representou aproximadamente 5\% dos gastos do primeiro trimestre de 2017. Conforme consta no relatório anual de 2016, o custo global da entidade no exercício de 2016 foi equivalente a $0,80 \%$ do patrimônio sob gestão.

Quanto às relações com os participantes da fundação, considerados como os clientes dos serviços prestados, segundo o entrevistado $\mathrm{B}$, o retorno é bastante positivo tanto dos participantes em atividade quanto dos aposentados, salvo raras exceções. Há casos pontuais de ações judiciais abertas pelos participantes contra a organização e, em 2016, o total de depósitos judiciais é pouco representativo (representa 0,44\% do
Patrimônio Social da entidade).

\subsection{Análise do Posicionamento Estratégico}

No que tange à análise do segundo ponto da Gestão Estratégica de Custos, foi observada uma posição de diferenciação perante os concorrentes. Várias são as características que colocam a entidade em uma situação diferenciada com relação ao mercado, e a conjugação dos fatores tanto de diferenciação como baixo custo são prioridades na entidade.

Diversos fatores contribuem para uma política de diferenciação. Ao questionar o Entrevistado B, responsável pelo relacionamento com os clientes, se tornou evidente $\mathrm{o}$ atendimento personalizado disponibilizado aos participantes - informação esta reforçada pelos demais colaboradores. Além disso, a instituição preocupa-se em gerar informação de interesse dos contribuintes atualizadas periodicamente em seu site e, recentemente, criou uma nova marca, mais moderna, porém preservando a essência da Fundação.

Quanto à questão da qualidade do serviço, foi questionado a todos os entrevistados sobre a opinião deles com relação à estratégia da entidade, se baseada em baixo custo, diferenciação ou enfoque (Porter, 1993). A resposta foi unânime: diferenciação. Por exemplo, o Entrevistado A,responsável pelo setor financeiro, argumentou: "se precisarmos comprar um computador, não vamos procurar pelo menor preço. Queremos qualidade - e qualidade de forma consciente" (Entrevistado A, 2017). Ou seja, a relação custo $\mathrm{x}$ benefício se mostrou sempre manifesta.

Diante do fato da entidade gerir recursos dos participantes, o setor de investimentos tem grande representatividade na totalidade do resultado. Alguns softwares de qualidade auxiliam neste gerenciamento, para melhor aplicação dos recursos e obtenção de retornos mais significativos.

Outro diferencial da Fundação é o serviço de empréstimos oferecido aos participantes, sem a necessidade de comprovação de renda, mediante desconto direto na folha de pagamentos de salários ou benefícios. Destaca-se que no setor de previdência complementar é comum a oferta de serviço de empréstimos pelos fundos de pensão aos seus participantes. Neste caso, a diferenciação não ocorre em comparação aos outros fundos de pensão, e sim em relação ao mercado externo, visto que, para o participante, as taxas de empréstimo com a entidade são muito mais atrativas do que nas demais instituições financeiras que este tem acesso.

Desta forma, os resultados encontrados com relação ao posicionamento estratégico, voltados para a diferenciação, corroboram com a teoria de Porter (1993) e Shank e Govindarajan (1997). Ainda, se comparados com os resultados do estudo de Piran et al. (2016), obteve uma conclusão semelhante, devido às 
características estratégicas convergentes apresentadas, baseadas na diferenciação.

\subsection{Análise dos Cost Drivers}

A análise dos Cost Drivers da fundação foi elaborada a partir dos 19 determinantes de custos propostos por Costa (2011). Observou-se que fatores de diversidade de máquinas e equipamentos, espaço físico, tempestividade, localização e diversidade de fornecedores e clientes não são determinantes diretos dos custos para a concessão dos benefícios. O Quadro 4 apresenta a análise dos Cost Drivers da entidade.

\begin{tabular}{|c|c|}
\hline Cost Drivers & Efeitos no cus to da entidade \\
\hline 1. Modelo de gestão & $\begin{array}{l}\text { A organização possui documentos oficiais, tais como Estatuto Social, Regulamento dos } \\
\text { Planos, Regimento Interno dos Conselhos, que influenciam no custo do serviço } \\
\text { prestado, servindo de diretriz para a entidade. }\end{array}$ \\
\hline 2. Escala & $\begin{array}{l}\text { A entidade, segundo a Previc (2016), é de médio porte. A automatização de } \\
\text { arrecadação das contribuições dos participantes ativos, é uma das principais atividades } \\
\text { de escala da organização. }\end{array}$ \\
\hline $\begin{array}{l}\text { 3. Utilização da } \\
\text { capacidade }\end{array}$ & $\begin{array}{l}\text { A entidade possui um quadro enxuto de colaboradores comprometidos, resultando em } \\
\text { um maior aproveitamento da capacidade dos recursos humanos. Por outro lado, o } \\
\text { espaço físico da sede é amplo para o número de colaboradores existentes. }\end{array}$ \\
\hline 4. Escopo & $\begin{array}{l}\text { A estrutura da entidade é utilizada em comum para a prestação dos benefícios } \\
\text { oferecidos, de ambos os Planos de Benefícios. Ou seja, uma mesma estrutura é } \\
\text { utilizada para a prestação de múltiplos serviços, impactando no custo desses. }\end{array}$ \\
\hline 5. Experiência & $\begin{array}{l}\text { A organização possui } 40 \text { anos de atuação, com constantes treinamentos e capacitação } \\
\text { dos colaboradores, bem como melhorias das atividades. Neste item, destaca-se o } \\
\text { mapeamento de processos, que está em andamento na entidade, como forma de } \\
\text { documentar adequadamente os registros das atividades internas. }\end{array}$ \\
\hline 6. Tecnologia & $\begin{array}{l}\text { As atualizações periódicas de softwares para as aplicações financeiras e demais } \\
\text { operações da área de investimentos, do CPD e para atendimento à Receita Federal, } \\
\text { entre outras, impactam no custo da organização. Por serem de valor expressivo, as } \\
\text { melhorias tecnológicas precisam estar previstas no orçamento anual e aprovadas pelo } \\
\text { Conselho Deliberativo da entidade. }\end{array}$ \\
\hline $\begin{array}{l}\text { 7. Diversidade de } \\
\text { produtos e serviços }\end{array}$ & $\begin{array}{l}\text { Há diversidade nos serviços prestados pela organização, uma vez que o Plano } 1 \text { possui } \\
\text { os benefícios de aposentadoria por tempo de serviço, por idade, por invalidez, } \\
\text { benefício proporcional diferido, auxílio-doença, auxílio-reclusão, pensão e pecúlio por } \\
\text { morte; e o Plano } 2 \text { possui os benefícios de aposentadoria normal, por invalidez, } \\
\text { benefício proporcional diferido, auxílio-doença e pensão por morte. }\end{array}$ \\
\hline $\begin{array}{l}\text { 8. Diversidade de } \\
\text { fornecedores }\end{array}$ & $\begin{array}{l}\text { Não há diversidade de fornecedores chave, uma vez que os serviços atuariais provêm } \\
\text { de uma única consultoria atuarial e as etapas de investimentos provêm, cada uma, de } \\
\text { uma única consultoria especializada. }\end{array}$ \\
\hline $\begin{array}{l}\text { 9. Diversidade de } \\
\text { clientes }\end{array}$ & $\begin{array}{l}\text { Não há diversidade de clientes, uma vez que o público alvo se restringe aos } \\
\text { funcionários do patrocinador e aos colaboradores da própria entidade. }\end{array}$ \\
\hline $\begin{array}{l}\text { 10. Diversidade de } \\
\text { máquinas e } \\
\text { equipamentos }\end{array}$ & Não é aplicável por tratar-se de prestação de serviços. \\
\hline 11. Comprometimento & $\begin{array}{l}\text { Os colaboradores da organização apresentam alto nível de comprometimento, } \\
\text { sinalizado em todas as cinco entrevistas individuais realizadas. Dois fatores } \\
\text { relacionados ao comprometimento são a baixa rotatividade e o pequeno número de } \\
\text { colaboradores. O nível de comprometimento afeta diretamente a redução do custo de } \\
\text { novas contratações e/ou rescisões. }\end{array}$ \\
\hline 12. Qualidade & $\begin{array}{l}\text { A adesão aos planos da entidade é de } 92 \% \text { do público alvo, representativamente alto } \\
\text { em comparação ao setor que, segundo o entrevistado C, é de aproximadamente } 70 \% \text {. } \\
\text { Este índice de adesão está relacionado à qualidade do serviço prestado. Para isso, a } \\
\text { gestão presa por fornecedores e equipamentos de qualidade, dos quais se sobressaia a } \\
\text { qualidade em detrimento do preço do insumo. Mesmo ponderando o custo-benefício da } \\
\text { compra, esta diretriz tende a elevar os custos da organização. }\end{array}$ \\
\hline 13. Arranjo físico & Não é aplicável por tratar-se de prestação de serviços. \\
\hline 14. Projeto de & Os planos de benefícios já passaram por alterações regulamentares ao longo de sua \\
\hline
\end{tabular}




\begin{tabular}{|c|c|}
\hline Cost Drivers & Efeitos no custo da entidade \\
\hline produto/s erviço & $\begin{array}{l}\text { história. Atualmente, o Plano } 2 \text { está em processo de alteração regulamentar, } \\
\text { modificando alguns aspectos dos benefícios oferecidos para melhor suprir as } \\
\text { necessidades dos participantes (como são benefícios de longo prazo, as necessidades } \\
\text { dos participantes podem mudar com o tempo, por isso é importante atualizações dos } \\
\text { produtos). }\end{array}$ \\
\hline $\begin{array}{l}\text { 15. Relações na cadeia } \\
\text { de valor }\end{array}$ & $\begin{array}{l}\text { A relação entre a consultoria atuarial e a área de previdência, consultorias de } \\
\text { investimento e área financeira, juntamente com a eficiente comunicação entre as áreas } \\
\text { internas e com os clientes (pós-venda), são fatores que influenciam o custo da } \\
\text { organização. }\end{array}$ \\
\hline $\begin{array}{l}\text { 16. Estrutura de } \\
\text { capitais e investimentos }\end{array}$ & $\begin{array}{l}\text { A estrutura de capitais da organização, quase em sua totalidade, é de recursos próprios, } \\
\text { denominado Patrimônio de Cobertura. Diferente das empresas privadas, essa é uma } \\
\text { característica do setor de previdência fechada, que deve garantir as obrigações por } \\
\text { meio de seu patrimônio próprio, sem a utilização de recursos de terceiros. A entidade } \\
\text { está de acordo com as normativas vigentes quanto a sua estrutura de capital, incluindo } \\
\text { as legislações pertinentes quanto aos limites de alocação dos recursos por tipo de } \\
\text { investimento (renda fixa, renda variável, imóveis, operações comparticipantes, etc.). }\end{array}$ \\
\hline 17. Tempestividade & $\begin{array}{l}\text { Não é aplicável devido à regulamentação legal rígida e ao posicionamento da entidade. } \\
\text { Não sofre pressão de concorrência do mercado, visto que está vinculada a um } \\
\text { patrocinador. }\end{array}$ \\
\hline 18. Localização & $\begin{array}{l}\text { O determinante de localização não influencia diretamente os custos da entidade, tendo } \\
\text { em vista que esse custo alinha-se aos preços de mercado. A localização da sede está } \\
\text { relacionada, por sua vez, com a arrecadação das receitas, em função da proximidade } \\
\text { com sede do patrocinador, que possibilita a captação de um maior número de } \\
\text { participantes. }\end{array}$ \\
\hline $\begin{array}{l}\text { 19. Fatores } \\
\text { institucionais }\end{array}$ & $\begin{array}{l}\text { Instituições normativas como o Conselho Nacional de Previdência Complementar } \\
\text { (CNPC), e fiscalizadores como a Superintendência Nacional de Previdência } \\
\text { Complementar (PREVIC), estabelecem normas que, por vezes, acabam por afetar o } \\
\text { custo da entidade, devido às sanções, multas, definição dos institutos para participantes } \\
\text { desligados do plano, certificação obrigatória dos conselheiros e dirigentes, entre outros. }\end{array}$ \\
\hline
\end{tabular}

Quadro 4 - Análise dos Cost Drivers da entidade

Nota.Fonte: dados obtidos na pesquis a (2017).

A partir do rol de determinantes propostos por Costa (2011), diante da adaptabilidade ao presente trabalho, foi possível evidenciar os principais Cost Drivers (Quadro 5) que influenciam os custos da entidade estudada. São eles: comprometimento dos colaboradores, experiência de 40 anos da fundação, qualidade do serviço prestado, tecnologia dos sistemas, modelo de gestão, escala, escopo e fatores institucionais dos órgãos normativos e fiscalizadores do setor de previdência complementar fechada.

Além disso, para a administração dos planos de benefícios, é estabelecido o Plano de Gestão Administrativa (PGA) da Entidade. O orçamento dos gastos, que compõe o PGA da entidade, é definido anualmente pelo contador e aprovado pelo Conselho Deliberativo, durante o exercício anterior ao de sua execução. O entrevistado D afirma que o orçamento anual é o norteador dos gastos a serem desembolsados ao longo do exercício. Segundo ele, caso seja necessária alguma compra não prevista no orçamento, a mesma será avaliada de forma detalhada e, obrigatoriamente, passará por aprovação especial do Conselho Deliberativo.
Ao realizar o comparativo com os demais estudos sobre Cost Drivers, é possível observar que as particularidades do setor de previdência complementar fechada fazem com que os principais determinantes de custos sejam diferentes de outros segmentos, como o da soja, que conforme a pesquisa de Carneiro, Duarte e Costa (2015), apresenta localização, tempestividade e estrutura de capitais dentre os Cost Drivers que mais impactam nos custos da atividade por estes estudada,

\section{DISCUSSÃO}

Para atingir o objetivo proposto, foi realizado um estudo de caso em um Fundo de Pensão brasileiro, considerado pela Previc (2016) como sendo de perfil médio. Dois planos de benefícios são administrados pela Entidade objeto de análise, ambos com resultado superavitário no ano de 2016. O estudo se deu pela triangulação da coleta dos dados, que se constituiu das técnicas de documentação, observação e entrevistas semiestruturadas. Assim sendo, a caracterização da Cadeia de Valor da referida entidade de previdência 
complementar parte dos fornecedores chave, que foram identificados como sendo os prestadores de serviço de consultoria atuarial e consultoria de investimentos.

Avançando para a cadeia de valor interna, tem-se o Setor de Benefícios, responsável pela captação e relacionamento com os participantes, seguido do Centro de Processamento de Dados (CPD), encarregado de arrecadar as contribuições dos adeptos aos planos. Para aplicação dos recursos recolhidos, o responsável é o Setor de Investimentos que conta, também, com o investimento de empréstimos aos participantes da fundação.

O CPD tem, ainda, a atribuição de conceder os benefícios (auxílio-doença, aposentadoria normal, aposentadoria por invalidez e pensão por morte) aos clientes, que podem ser ativos, aposentados ou pensionistas. A cadeia de valor interna conta ainda com as atividades de apoio de contabilidade, infraestrutura do local e recursos humanos, além da atividade externa de apoio prestada pela consultoria jurídica. Os órgãos normativos e fiscalizadores do setor de Previdência Complementar Fechada afetam a Cadeia de Valor da entidade, tanto interna quanto externamente. Os resultados vão de encontro aos obtidos por Vesco et al. (2014) e El-Sayed, Dickson e El-Naggar (2015), que adaptaram o modelo de Cadeia de Valor proposto por Porter (1993) aos respectivos setores estudados.

Partindo para análise do Posicionamento Estratégico do Fundo de Pensão, identificou-se a predominância da estratégia de diferenciação, corroborando com as conclusões de Piran et al. (2016). Com relação aos Cost Drivers, partiu-se dos determinantes de custos propostos por Costa (2011), dos quais se concluiu que os principais que influenciam os custos da Entidade são: comprometimento, experiência, qualidade, tecnologia, modelo de gestão, escopo, escala e fatores institucionais da organização.

Ademais, como limitação da presente pesquisa observa-se a particularidade que remete ao estudo de caso, em especial diante da possível generalização dos resultados. É importante salientar que o produto desta pesquisa se limita às peculiaridades da entidade estudada, não podendo ser universalizada a outros tipos de organização. No entanto, cabe destacar que a realização da triangulação de dados aumenta a confiabilidade da interpretação dos resultados do estudo, reduzindo o escopo da limitação do método utilizado.

\section{CONSIDERAÇÕES FINAIS}

A Gestão Estratégica de Custos (GEC) se apresenta como um importante instrumento de auxílio às tomadas de decisão das empresas, decisões estas que impactam diretamente em sua vantagem competitiva com relação aos concorrentes. Diante deste cenário, o objetivo do presente estudo foi identificar como se caracterizam os três temas chaves da GEC, sejam eles a
Cadeia de Valor, o Posicionamento Estratégico e os Cost Drivers, em uma Entidade Fechada de Previdência Complementar do Brasil, adaptando as diretrizes originalmente propostas por Shank e Govindarajan (1993) e Costa (2011).

A partir da proposta de pesquisa e dos pontos abordados, foi possível identificar como se configura a Gestão Estratégica de Custos de um Fundo de Pensão. Diante da representatividade do setor de previdência complementar, e do momento oportuno, visto das especulações relativas à reforma da previdência, foi possível contribuir com a análise teórica e estratégica, voltada para este setor. Mesmo que o segmento forneça serviços, e não produtos, como é corriqueiro nas análises de GEC, foi possível a adaptação a este ramo, em evidência no atual cenário nacional.

Como sugestão para pesquisas futuras, propõe-se a realização da análise da Gestão Estratégica de Custos em outras entidades do mesmo setor, para comparação de resultados. Ainda, recomenda-se efetuar a análise da Cadeia de Valor do mercado de Entidades Abertas de Previdência Complementar, com posterior verificação da vantagem competitiva deste mercado que possuem um regime equiparado ao das instituições financeiras e visamlucro; diferentemente das entidades fechadas, onde o valor arrecadado é destinado exclusivamente ao benefício de seus participantes e manutenção da instituição.

Assim, diante do exposto, este estudo, que vislumbra a configuração dos elementos da GEC na prática da previdência complementar fechada, consolida-se como fonte de consulta para futuras pesquis as sobre a área de gestão e estratégia direcionada às especificidades dos fundos de pensão brasileiros, que se farão necessárias ao longo dos próximos anos devido às transformações políticas, econômicas e sociais que se encaminham no âmbito da previdência do país, de forma que os fundos de pensão e demais agentes envolvidos neste segmento possam valer-se de análises de cadeia de valor, posicionamento estratégico e Cost Drivers em suas estratégias, adaptando-se às mudanças estruturais que estão por vir.

\section{REFERÊNCIAS}

Amara, N., Halilem, N. \& Traoré, N. (2016). Adding value to companies' value chain: role of business. JournalofBusiness Research, 69,1661-1668.

Associação Brasileira Das Entidades Fechadas De Previdência Complementar (ABRAPP). (2017). Consolidado Estatístico de março 201. Recuperado em 30 abril, 2017, de

http://www.abrapp.org.br/Paginas/cons olidadoestatis tic o.aspx

Brasil. Ministério da Previdência Social. Previdência Complementar: cartilha do participante. 2008. 
Recuperado em 20 abril, 2017, de http://www.previdencia.gov.br/arquivos/office/3_0901 19-102133-452.pdf

Brasil. Presidência da República. Lei Complementar $n^{o}$ 109, de 29 de maio de 2001. Dispõe sobre o Regime de Previdência Complementar e dá outras providências. 2001. Recuperado em 18 abril, 2017, de http://www.planalto.gov.br/ccivil_03/leis/LCP/Lcp 109. htm

Caetano, M. A. (2014). Economias de escala e escopo na previdência complementar fechada brasileira. Textos para discussão - IPEA,Rio de Janeiro, 1954, 1-62.

Carneiro, D. M., Duarte, S. L. and Costa, S. A. (2015). Determinantes dos custos da produção de soja no Brasil. In: Congresso Brasileiro De Custos, 22., 2015, Anais... Foz do Iguaçu: As sociação Brasileira de Custos.

Catanio, A. R., Santos, E. F. and Abbas, K. (2015). Ensaio teórico sobre cost drivers: determinantes de custos e direcionadores de custos. In: Congresso Brasileiro De Custos, 22., 2015, Anais...Foz do Iguaçu: Associação Brasileira de Custos.

Cavalcanti, M. A. N., Ferreira, H. M. C. and Araujo; A.(2013) O. Análise do posicionamento estratégico para implementação da gestão estratégica de custos: um estudo de caso em uma empresa do setor de beneficiamento de aço inoxidável. Revista Ambiente Contábil,Natal,5 (1), 75-92.

Ceptureanu,E. G. (2016).Competitive Intensity and Its Implication on Strategic Position of Companies. Journal Of Applied Quantitative Methods, 11 (1).

Costa, S. A. Análise de custos concorrentes: um estudo dos determinantes de custos no setor de eletroeletrônicos. (2011). 205 f. Dis sertação (Mestrado em Ciências Contábeis ) - Faculdade de Economia, Administração e Contábeis, Universidade de São Paulo, São Paulo.

Costa, S. A., Carneiro, D. M. (2014). Determinantes de Custos: uma proposta de taxonomia e agrupamento. In: CONGRESSO BRASILEIRO DE CUSTOS, 21., 2014.Anais... Natal: Associação Brasileira de Custos.

El-Sayed, A. F. M., Dickson, M. W. and El-Naggar, G. O. (2015). Value chain analysis of the aquaculture feed sectorin Egypt.Aquaculture, 437, 92-101.

Fullerton, R. R., Kennedy, F. A. and Widener, S. K. (2014). Lean manufacturing and firm performance: The incremental contribution of lean management accounting practices. JournalofOperations Management, 32, 414-428.
Guerra, J. H. L. (2010) Proposta de um protocolo para o estudo de caso em pesquisas qualitativas. In: Encontro Nacional De Engenharia De Produção, 30, 2010, São Carlos. Anais...Rio de Janeiro:ABEPRO.

Gil, A. C. (2008) Como elaborarprojetos de pesquisa. (4n ed). São Paulo: Atlas.

Hald, K. S. \& Thrane, S. (2016) Management Accounting and Supply Chain Strategy. In: $1 s t$ InternationalCompetitiveness Management Conference.

Krielow, A. and Santos, M. R. A Definição do Posicionamento Estratégico sob a perspectiva das competências organizacionais para obtenção de vantagem competitiva. In: Encontro Da Associação Nacional De Pós-Graduação Em Administração Enanpad, 38., 2014, Anais... Rio de Janeiro:

Associação Nacional de Pós-Graduação e Pesquisa em Adminis tração, 2014.

Malmia, T. (2016) Managerialist studies in management accounting: 1990-2014. Management AccountingResearch, 31, 31-44.

Martins, G. A. and Theóphilo, C. R. (2009). Metodologia da investigação científica para ciências sociais aplicadas. (2nd ed). São Paulo: Atlas.

Mol, A. P. J. (2015). Transparency and value chain sustainability. Journal of Cleaner Production, 107, 154-161.

Piran, F. A. S., Nunes, A. A. B., Souza, M. A. and Nunes, F. L. (2016).Posicionamento estratégico, estratégias de manufatura e gestão de custos: estudo de caso em uma empresa do segmento metal mecânico.Revista Contemporânea de Contabilidade, Florianópolis, 28, 81-98.

Porter, M. E. (1993). A vantagem competitiva das nações.Rio de Janeiro: Campus.

Porter, M. E. (1989). Vantagem competitiva: criando e sustentando um desempenho superior. (33nd ed). Rio de Janeiro: Campus .

Raupp, S. W., Borgert, A., Nunes, P. and Ferrari, M. J. (2012)O processo de implementação da Gestão Estratégica de Custos em uma empresa estatal de energia elétrica. Revista Eletrônica Estratégiae Negócios, Florianópolis, 5 (1), 137-166.

Rocha, W.\& Borinelli, M. L. (2007) Análise estratégica de cadeia de valor: um estudo exploratório do segmento indústria-varejo. Revista Contemporânea de Contabilidade,Florianópolis, 7 (1),145-165. 
Silva, J. C. P. A. (2003). Previdência Complementar Privada e Fechada (Fundos de Pensão). Revista da EMERJ, Rio de Janeiro, 21 (6), 121-133.

Silva, J. F., Filho, W. P. F., Carneiro, J. M. T and Ferreira, J. B. (2013). Strategic positioning and strategic stability: does it matter to performance?.Revista Ibero-Americana de Estratégia, São Paulo, 12 (4), 09-39.

Shank, J. K. and Govindarajan, V. (1997). A revolução dos custos. (2nd ed). Rio de Janeiro: Campus.

Souza, A. A., Guerra, M., Lara, C. O., Avelar, E. A. and Amorim, T. L. M. (2009) Gestão Estratégica de Custos em organizações hospitalares. In: Encontro Nacional De Engenharia De Produção, 29., 2009, Anais... Salvador: Ass ociação Brasileira de Engenharia de Produção.

Souza, M.A.; Silva, E. J.; Pilz, N. (2010)Práticas de Gestão Estratégica de Custos: um estudo em uma empresa multinacional brasileira. Revista de Contabilidade e Organizações, São Paulo, 9 (4), 145167.

Superintendência Nacional De Previdência Complementar(PREVIC). (2017) Estatística Trimestral
- Março 2017. Recuperado em 30 abril, 2017, de http://www.previc.gov.br/central-de-

conteudos/informe-estatistico/informes-de-2017

Superintendência Nacional De Previdência Complementar (PREVIC). (2016).Portaria $n^{\circ} 465$, de 29 de setembro de 2016. Dispõe sobre a classificação das entidades fechadas de previdência complementar (EFPC) em perfis, para fins de supervisão no âmbito da PREVIC, a partir do exercício de 2017. Recuperado em 24 abril, 2017, de http://www.previc.gov.br/aprevidencia-complementar-fechada/legis lacaoespecifica-1/portarias/2016/

Terpstra, M. and Verbeeten, F. H. M. (2014). Costumer satisfaction: Cost driver or value driver? Empirical evidence from the financial services industry. European Management Journal, 32, 499-508.

Vesco, D. G. D., Tarifa, M. F., Pacheco, V. and Dall'Asta, D. (2014) Cadeia de valores na gestão de custos:uma análise estratégica em cooperativas agropecuárias paranaenses. Revista Ibero-Americana de Estratégia, São Paulo, 13 (2), 83-98.

Yin, R. K. (2015) Estudo de caso: planejamento e métodos. 5. ed. Porto Alegre: Bookman. 